\title{
Grupo de Inteligência Artificial da Faculdade de Computação da Universidade Federal de Uberlândia
}

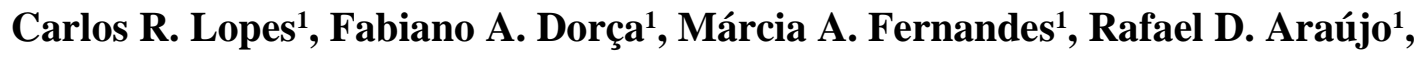 \\ Renan G. Cattelan ${ }^{1}$
}

${ }^{1}$ Faculdade de Computação (FACOM) - Universidade Federal de Uberlândia (UFU)

Caixa Postal 15.064 - 91.501-970 - Porto Alegre - RS - Brazil

\{crlopes, fabianodor, marcia, rafael, renan\} @ufu.br

O Grupo de Inteligência Artificial da Faculdade de Computação da Universidade Federal de Uberlândia tem atuado em Informática na Educação desde 2001. Os principais objetivos do grupo de pesquisa são:

- aplicar técnicas de Inteligência Artificial no desenvolvimento de sistemas adaptativos e inteligentes para Educação a Distância e Computação Ubíqua

- desenvolver algoritmos de Busca e Recuperação de Objetos de Aprendizagem adaptados ao Aprendiz

- desenvolver Objetos de Aprendizagem para o Ensino de Matemática e Ciências

- aplicar Robótica Educativa no Ensino de Matemática e Ciências

Os seguintes pesquisadores compõem o grupo de pesquisa: Arlindo José de Sousa Júnior (Faculdade de Matemática - UFU), Bruno Queiroz Pinto (Instituto Federal do Triângulo Mineiro), Carlos Roberto Lopes (FACOM-UFU), Fabiano Azevedo Dorça (FACOM-UFU), José dos Reis Mota (Centro Universitário de Patos de Minas), Rejane Maria Silva (UFSC), Rafael Araújo (FACOM-UFU), Renan Cattelan (FACOM-UFU) e Robson da Silva Lopes (UFMT).

A seguir destacamos alguns dos projetos desenvolvidos/em desenvolvimento pelo grupo com a descrição da entidade fomentadora.

- Sistema Inteligente Multiagente para Educação a Distância (Período: 2001-2005 financiado por CAPES e FAPEMIG).

- Projeto RIVED (Período: 2004-2010 financiado por MEC). Robótica Educacional (Período: 2008-2010 financiado pela FAPEMIG)

- Modelagem Automática e Dinâmica de Estilos de Aprendizagem Baseada em Aprendizagem por Reforço (Período: 2010 com financiamento UFU)

- Captura e Acesso Na Produção, Distribuição, Apresentação E Extensão De Conteúdo Multimídia (Período: 2011-2013 com financiamento FAPEMIG)

- Desenvolvimento De Uma Estratégia De Ensino Apoiada Em Processos De Decisão Markovianos Para Ambientes Virtuais De Aprendizagem (Período: 2013 - FAPEMIG) 